\title{
MENINGKATKAN KOMPETENSI GURU DALAM MENYUSUN RENCANA PELAKSANAAN PEMBELAJARAN KURIKULUM 2013 MELALUI PEMBIMBINGAN DAN PELATIHAN PROFESIONAL OLEH PENGAWAS SEKOLAH DI SMK GALUNGGUNG KOTA TASIKMALAYA TAHUN 2016
}

\author{
Usep Saepudin ${ }^{1}$ \\ Pengawas Sekolah Madya Kota Tasikmalaya \\ Jalan Gudang Jero III No.21, Panglayungan, Cipedes, Tasikmalaya, Jawa Barat 46134
}

\begin{abstract}
ABSTRAK
Metode yang digunakan dalam penelitian ini adalah metode deskriptif, dengan menggunakan teknik presentase untuk melihat peningkatan yang terjadi dari siklus ke siklus. Pada pelaksanaan tindakan siklus I terlihat guru-guru masih belajar memahami dalam pembuatan RPP Kurikulum 2013. Hal ini dapat dilihat dari perolehan skor Yeri Maesuri, S.Pd mendapat skor 57,50\%, Subhanulfalah, ST mendapat skor 55,00\% , Tessa.W, ST mendapat skor 52,50\% dan Eman Sulaeman, S.Pd mendapat skor $52,50 \%$. Hasil evaluasi pada siklus pertama mencapai rata-rata 54,34\%. Artinya guru-guru masih dalam tarap pembelajaran dalam memahami dan membuat RPP Kurikulum 2013. Pada pelaksanaan siklus II terlihat para guru-guru sudah memahami dalam pembuatan RPP Kurikulum 2013. Hal ini dapat dilihat dari perolehan skor Yeri Maesuri, S.Pd pada siklus I mendapat skor 57,50\% dan pada siklus II skor $85,00 \%$, Subhanulfalah, ST pada siklus I mendapat skor $55,00 \%$ dan pada siklus II skor $87,50 \%$, Tessa W, ST pada siklus I mendapat skor 52,50\% dan pada siklus II skor 82,50\%, Eman Sulaeman, S.Pd pada siklus I skor $52,50 \%$ dan pada siklus II skor $85,00 \%$. Hasil evaluasi pada siklus II mencapai rata-rata $85,00 \%$. Sedangkan siklus I rata-rata 54,34\%. Artinya ada peningkatan $30,66 \%$. Hal ini menunjukkan bahwa melaui bimbingan dan latihan profesional, komoetensi guru dalam pembuatan RPP Kurikulum 2013 meningkat.
\end{abstract}

Kata Kunci: Kompetensi guru, Perangkat pembelajaran dan Kurikulum 2013

\begin{abstract}
The method used in this research is descriptive method, using percentage techniques to see the increase that occurs from cycle to cycle. In the implementation of the first cycle of action seen the teachers are still learning to understand in the preparation of the 2013 Curriculum RPP. This can be seen from the acquisition of scores Yeri Maesuri, S.Pd scored 57.50\%, Subhanulfalah, ST got a score of 55.00\%, Tessa. W, ST got a score of 52.50\% and Eman Sulaeman, S.Pd got a score of 52.50\%. The evaluation results in the first cycle reached an average of $54.34 \%$. This means that the teachers are still in the learning process in understanding and making the 2013 curriculum lesson plan. In the implementation of the second cycle, the teachers already understood the preparation of the 2013 curriculum curriculum. This can be seen from the scores obtained by Yeri Maesuri, S.Pd in the first cycle. the score was $57.50 \%$ and in the second cycle the score was $85.00 \%$, Subhanulfalah, ST in the first cycle got a score of $55.00 \%$ and in the second cycle the score was $87.50 \%$, Tessa W, ST in the first cycle got a score of $52.50 \%$ and in the second cycle the score was $82.50 \%$, Eman Sulaeman, S.Pd in the first cycle the score was $52.50 \%$ and in the second cycle the score was $85.00 \%$. The evaluation results in the second cycle reached an average of $85.00 \%$. While the first cycle averaged $54.34 \%$. This means that there is an increase of $30.66 \%$. This shows that through professional guidance and training, teacher competence in the preparation of the 2013 curriculum curriculum is increasing.
\end{abstract}

Keywords: Teacher competencies, learning tools and 2013 curriculum

\footnotetext{
${ }^{1}$ Penulis Koresponden

E-mail address: usepsaepudin165@gmail.com doi: $10.25157 /$ ja.v6i1.2044
} 


\section{PENDAHULUAN}

Kurikulum sebagai salah satu substansi pendidikan perlu didesentralisasikan terutama dalam pengembangan KTSP dan pelaksanaannya yang disesuaikan dengan tuntutan kebutuhan siswa, keadaan sekolah, dan kondisi sekolah atau daerah. Dengan demikian, sekolah atau daerah memiliki kewenangan untuk merancang dan menentukan materi pokok/pembelajaran, kegiatan pembelajaran, dan penilaian hasil pembelajaran.

Banyak hal yang perlu dipersiapkan oleh daerah karena sebagian besar kebijakan yang berkaitan dengan implementasi Standar Nasional Pendidikan dilaksanakan oleh sekolah atau daerah. Sekolah harus menyusun Kurikulum Tingkat Satuan Pendidikan (KTSP) yang terdiri dari tujuan pendidikan tingkat satuan pendidikan, struktur dan muatan kurikulum, kalender pendidikan, silabus dan RPP dengan cara melakukan penjabaran dan penyesuaian Standar Isi yang ditetapkan dengan Permendikbud No. 60 Tahun 2014 dan Standar Kompetensi Lulusan yang ditetapkan dengan Permendikbud No. 54 Tahun 2014

Di dalam Peraturan Pemerintah Nomor 19 tahun 2005 tentang Standar Nasional Pendidikan dijelaskan:

1. Sekolah dan komite sekolah/madrasah, mengembangkan kurikulum tingkat satuan pendidikan dan silabusnya berdasarkan kerangka dasar kurikulum dan standar kompetensi lulusan di bawah supervisi Dinas Pendidikan Kabupaten/Kota yang bertangung jawab terhadap pendidikan untuk TK, SMP, SMA, dan SMK, serta Departemen yang menangani urusan pemerintahan di bidang agama untuk MI, MTs, MA, dan MAK ( Pasal 17 Ayat 2).

2. Perencanan proses pembelajaran meliputi silabus dan rencana pelaksanan pembelajaran yang memuat sekurang-kurangnya tujuan pembelajaran, materi ajar, metode pengajaran, sumber belajar, dan penilaian hasil belajar (Pasal 20).

Berdasarkan ketentuan di atas, daerah atau sekolah memiliki ruang gerak yang luas untuk melakukan modifikasi dan mengembangkan variasi-variasi penyelengaraan pendidikan yang sesuai dengan keadaan, potensi, dan kebutuhan daerah, serta kondisi siswa. Untuk keperluan di atas, perlu adanya panduan pengembangan RPP untuk setiap mata pelajaran, agar daerah atau sekolah tidak mengalami kesulitan dalam memahami dan membuat RPP di sekolah.

Pengawas Satuan Pendidikan merupakan tenaga kependidikan mutlak terstandarisasi kompetensinya secara nasional menurut PP No 19 tahun 2005 di atas, yakni standar pendidik dan tenaga kependidikan nasional. Karena Pengawas Sekolah/madrasah adalah salah satu unsur yang berperan aktif dalam lembaga pendidikan (persekolahan). Pengawas Satuan Pendidikan adalah pelaku pendidikan didalam pelaksanaan tugas kepengawasan pendidikan yang meliputi tiga aspek yaitu supervisi, pengendalian (kontroling) dan inspeksi kependidikan.

Untuk meningkatkan mutu pendidikan, pengawas dituntut keprofesionalannya untuk melaksanakaan tugas pokok dan fungsinya sesuai kompetensinya. Karena tugas pengawas sangat erat kaitannya dengan penjaminan mutu pendidikan di suatu lembaga persekolahan.

Usaha apapun yang telah dilakukan pemerintah mengawasi jalannya pendidikan untuk mendobrak mutu bila tidak ditindak lanjuti dengan pembinaan gurunya, maka tidak akan berdampak nyata pada kegiatan layanan belajar dikelas. Kegiatan pembinaan guru merupakan bagian yang tak terpisahkan dalam setiap usaha peningkatan mutu pembelajaran (Dadang suhardan, 2006 : 9). Disatu pihak peranan Pengawas satuan Pendidikan didalam pembinaan profesional guru sangat signifikan terhadap produktivitas dan efektifitas kinerja guru tersebut. Masalah dukungan kemudahan dan faktor rintangan pelaksanaan pemberian bantuan profesional kepada guru tampaknya disadari sebagai sesuatu aspek yang tidak bisa dilepaskan dari seluruh keberhasilan kegiatan upaya peningkatan mutu pembelajaran.

LAN (2004) seperti yang dikutip Suradji dalam Ridwan (2009 : 269) menyatakan bahwa: "Kinerja atau performansi dapat diartikan sebagai prestasi kerja, pencapaian kerja, hasil kerja atau unjuk kerja". Dengan demikian diduga ada dua variabel sebagai penyebab rendahnya kinerja profesional guru yaitu varibel supervisi pengawas dan kepemimpinan kepala sekolah dalam penciptaan iklim kerja (iklim sekolah) yang kurang kondusif bagi pengembangan produktivitas kinerja guru.

Dari dua variabel tersebut dilakukan pengamatan dan analisis patut diduga yang menjadi penyebab rendahnya kinerja pengawas (perilaku kepengawasan) antara lain belum terpenuhinya standar kompetensi pengawas 


\section{Usep Saepudin}

Meningkatkan Kompetensi Guru Dalam Menyusun Rencana Pelaksanaan Pembelajaran Kurikulum 2013

Melalui Pembimbingan Dan Pelatihan Profesional Oleh Pengawas Sekolah Di SMK Galunggung

Kota Tasikmalaya Tahun 2016

satuan pendidikan dalam hal: (1) kepribadian, (2) supervisi akademik, (3) supervisi manajerial, (4) sosial, (5) evaluasi pendidikan, dan (6) penelitian pengembangan.

Pada kenyataannya guru-guru di sekolah binaan dalam hal ini SMK Galunggung Tasikmalaya, masih kurang memahami langkahlangkah dalam menyusun RPP. Hal ini dikarenakan sosialisasi KTSP Kurikulum 2013 untuk masing-masing mata pelajaran belum merata, penafsiran tentang RPP masih simpang siur. Kemampuan dalam menyusun RPP masih rendah. Hal ini akan berakibat pada pelaksanaan pembelajaran dan akan berimbas pada mutu proses pembelajaran yang pada akhirnya akan berpengaruh terhadap hasil belajar yang kurang memuaskan. Kondisi yang diharapkan pada saat ini adalah bahwa guru sebelum melaksanakan KBM harus menguasai dulu silabus, kemudian dari silabus dijabarkan dalam pembuatan RPP.

Berdasarkan uraian di atas para guru di sekolah binaan memerlukan bimbingan, pengarahan dan pembinaan dari Pengawas Sekolah, agar pemahaman terhadap menyusun RPP tersebut dapat meningkat. Mengingat hal tersebut penulis mengadaan penelitian tindakan sekolah dengan mengambil judul penelitian “ Meningkatlan Kompetensi Guru Dalam Menyusun Rencana Pelaksanaan Pembelajaran Kurikulum 2013 Melalui Pembimbingan dan Pelatihan Profesional oleh Pengawas Sekolah di SMK Galunggung Kota Tasikmalaya Tahun 2016".

\section{METODE PENELITIAN}

Penelitian ini berbentuk Penelitian Tindakan Sekolah, yaitu sesuah penelitian yang merupakan kerjasama antara peneliti dan guru, dalam meningkatkan kemampuan guru agar menjadi lebih baik dalam menyusun rencana pelaksanaan pembelajaran

Metode yang digunakan dalam penelitian ini adalah metode deskriptif, dengan menggunakan teknik presentase untuk melihat peningkatan yang terjadi dari siklus ke siklus. Metode deskriptif dapat diartikan sebagai prosedur pemecahan masalah yang diselidiki dengan menggambarkan/melukiskan keadaan subjek/objek penelitian (sesorang, lembaga, masyarakat, dan lain-lain) pada saat sekarang berdasarkan fakta-fakta yang tampak atau sebagaimana adanya (Nawawi, 1985:63). Dengan metode ini peneliti berupaya menjelaskan data yang peneliti kumpulkan melalui komunikasi langsung atau wawancara, observasi/pengamatan, dan diskusi yang berupa persentase atau angka-angka.

\section{HASIL PENELITIAN DAN PEMBAHASAN}

\section{Hasil Penelitian \\ Siklus 1}

Hasil observasi pengawas sekolah dalam pelaksanaan administrasi kurikulum selama siklus pertama dapat dilihat pada tabel berikut.

Tabel 4.1

Perolehan Skor Pemahaman dan Pembuatan RPP Siklus I

\begin{tabular}{|c|c|c|c|c|c|c|c|}
\hline \multicolumn{8}{|c|}{ Nama Guru : Yeri Maesuri, S.Pd } \\
\hline No & Indikator & 4 & 3 & 2 & 1 & $\%$ & Ket \\
\hline 1 & Identitas Mata Pelajaran & & $\mathrm{v}$ & & & 75 & Sedang \\
\hline 2 & Kompetensi Inti & & $\mathrm{V}$ & & & 75 & \\
\hline 3 & Kompetensi Dasar & & $\mathrm{v}$ & & & 75 & \\
\hline 4 & Indikator Pencapaian Kompetensi & & & & $\mathrm{v}$ & 25 & Sangat \\
\hline 5 & Tuiuan Pembelaiaran & & & $\mathrm{y}$ & & 50 & $\begin{array}{l}\text { Rendah } \\
\text { Rendah }\end{array}$ \\
\hline 6 & Materi Pembelajaran & & & $\mathrm{V}$ & & 50 & \\
\hline 7 & Model dan Metode & & & $\mathrm{v}$ & & 50 & \\
\hline 8 & Kegiatan Pembelajaran & & & & $\mathrm{V}$ & 25 & \\
\hline 9 & Media, Alat/Bahan, dan Sumber Belajar & & $\mathrm{v}$ & & & 75 & \\
\hline 10 & Penilaian Pembelajaran, Remedial dan Pengayaan & & $\mathrm{v}$ & & & 75 & \\
\hline & Jumlah 23 & & 15 & 6 & 2 & & \\
\hline & Prosentase & & :40x 1 & $0 \%$ & $57->>>>$ & $\%(1$ & rang) \\
\hline
\end{tabular}


Tabel 4.2

Perolehan Skor Pemahaman dan Pembuatan RPP Siklus I

\begin{tabular}{|c|c|c|c|c|c|c|c|}
\hline \multicolumn{8}{|c|}{ Nama Guru : Subhanulfalah, S.T } \\
\hline No & Indikator & 4 & 3 & 2 & 1 & $\%$ & Ket \\
\hline 1 & Identitas Mata Pelajaran & & $\mathrm{v}$ & & & 75 & Sedang \\
\hline 2 & Kompetensi Inti & & $\mathrm{v}$ & & & 75 & \\
\hline 3 & Kompetensi Dasar & & $\mathrm{v}$ & & & 75 & \\
\hline 4 & Indikator Pencapaian Kompetensi & & & & $\mathrm{v}$ & 25 & Sangat \\
\hline & & & & & & & Rendah \\
\hline 5 & Tujuan Pembelajaran & & & & $\mathrm{V}$ & 25 & \\
\hline 6 & Materi Pembelajaran & & & $\mathrm{V}$ & & 50 & Rendah \\
\hline 7 & Model dan Metode & & & $\mathrm{v}$ & & 50 & \\
\hline 8 & Kegiatan Pembelajaran & & & $\mathrm{v}$ & & 50 & \\
\hline 9 & Media, Alat/Bahan, dan Sumber Belajar & & $\mathrm{V}$ & & & 75 & \\
\hline 10 & Penilaian Pembelajaran, Remedial dan Pengayaan & & & $\mathrm{V}$ & & 50 & \\
\hline & Jumlah 22 & & 12 & 8 & 2 & & \\
\hline & Prosentase & & $40 \mathrm{x}$ & $0 \%$ & & $\%$ & Irang) \\
\hline
\end{tabular}

Tabel 4.3

Perolehan Skor Pemahaman dan Pembuatan RPP Siklus I

\begin{tabular}{|c|c|c|c|c|c|c|c|}
\hline \multicolumn{8}{|c|}{ Nama Guru : Tessa W, ST } \\
\hline No & Indikator & 4 & 3 & 2 & 1 & $\%$ & Ket \\
\hline 1 & Identitas Mata Pelajaran & & $\mathrm{v}$ & & & 75 & Sedang \\
\hline 2 & Kompetensi Inti & & $\mathrm{v}$ & & & 75 & \\
\hline 3 & Kompetensi Dasar & & $\mathrm{v}$ & & & 75 & \\
\hline 4 & Indikator Pencapaian Kompetensi & & & & $\mathrm{v}$ & 25 & $\begin{array}{l}\text { Sangat } \\
\text { rendah }\end{array}$ \\
\hline 5 & Tujuan Pembelajaran & & & & $\mathrm{V}$ & 25 & \\
\hline 6 & Materi Pembelajaran & & & $\mathrm{V}$ & & 50 & Rendah \\
\hline 7 & Model dan Metode & & & $\mathrm{v}$ & & 50 & \\
\hline 8 & Kegiatan Pembelajaran & & & $\mathrm{v}$ & & 50 & \\
\hline 9 & Media, Alat/Bahan, dan Sumber Belajar & & & $\mathrm{v}$ & & 50 & \\
\hline 10 & Penilaian Pembelajaran, Remedial dan Pengayaan & & & $\mathrm{v}$ & & 50 & \\
\hline & Jumlah 21 & & 9 & 10 & 2 & & \\
\hline & Prosentase & 21: & $\mathbf{x} 1$ & $\%=$ & & (ku & ng) \\
\hline
\end{tabular}

Tabel 4.4

Perolehan Skor Pemahaman dan Pembuatan RPP Siklus I

\begin{tabular}{|c|c|c|c|c|c|c|c|}
\hline \multicolumn{8}{|c|}{ Nama Guru : Eman Sulaeman, S.Pd } \\
\hline No & Indikator & 4 & 3 & 2 & 1 & $\%$ & Ket \\
\hline 1 & Identitas Mata Pelajaran & & $\mathrm{v}$ & & & 75 & \\
\hline 2 & Kompetensi Inti & & $\mathrm{v}$ & & & 75 & Sedang \\
\hline 3 & Kompetensi Dasar & & $\mathrm{v}$ & & & 75 & \\
\hline 4 & Indikator Pencapaian Kompetensi & & & & $\mathrm{V}$ & 25 & Sangat Rendah \\
\hline 5 & Tujuan Pembelajaran & & & & $\mathrm{v}$ & 25 & \\
\hline 6 & Materi Pembelajaran & & & $\mathrm{V}$ & & 50 & Rendah \\
\hline 7 & Model dan Metode & & & $\mathrm{v}$ & & 50 & \\
\hline 8 & Kegiatan Pembelajaran & & & $\mathrm{v}$ & & 50 & \\
\hline 9 & Media, Alat/Bahan, dan Sumber Belajar & & & $\mathrm{V}$ & & 50 & \\
\hline 10 & Penilaian Pembelajaran, Remedial dan & & & $\mathrm{v}$ & & 50 & \\
\hline & $\begin{array}{l}\text { Pengayaan } \\
\text { Jumlah } 21\end{array}$ & & 9 & 10 & 2 & & \\
\hline & Prosentase & & $\mathbf{x} 10$ & $=5$ & 0 & $(\mathbf{k u}$ & \\
\hline
\end{tabular}




\section{Usep Saepudin}

Meningkatkan Kompetensi Guru Dalam Menyusun Rencana Pelaksanaan Pembelajaran Kurikulum 2013 Melalui Pembimbingan Dan Pelatihan Profesional Oleh Pengawas Sekolah Di SMK Galunggung

Kota Tasikmalaya Tahun 2016

\section{Siklus 2}

Hasil observasi pelaksanaan pembuatan RPP Kurikulum 2013 selama siklus kedua dapat dilihat pada tabel beriikut ini.

Tabel 4.5

Perolehan Skor Pemahaman dan Pembuatan RPP Siklus II

\begin{tabular}{|c|c|c|c|c|c|c|c|}
\hline \multicolumn{8}{|c|}{ Nama Guru :Yeri Maesuri, S.Pd } \\
\hline No & Indikator & 4 & \begin{tabular}{|c|cr}
3 \\
$\mid$
\end{tabular} & 2 & 1 & $\%$ & Ket \\
\hline 1 & Identitas Mata Pelajaran & $\mathrm{v}$ & & & & 100 & Tinggi \\
\hline 2 & Kompetensi Inti & $\mathrm{v}$ & & & & 100 & \\
\hline 3 & Kompetensi Dasar & $\mathrm{v}$ & & & & 100 & \\
\hline 4 & Indikator Pencapaian Kompetensi & & $\mathrm{V}$ & & & 75 & Sedang \\
\hline 5 & Tujuan Pembelajaran & & $\mathrm{v}$ & & & 75 & \\
\hline 6 & Materi Pembelajaran & $\mathrm{V}$ & & & & 100 & \\
\hline 7 & Model dan Metode & & $\mathrm{V}$ & & & 75 & \\
\hline 8 & Kegiatan Pembelajaran & & $\mathrm{v}$ & & & 75 & \\
\hline 9 & Media, Alat/Bahan, dan Sumber Belajar & & $\mathrm{v}$ & & & 75 & \\
\hline 10 & Penilaian Pembelajaran, Remedial dan & & $\mathrm{v}$ & & & 75 & \\
\hline & Pengayaan & & & & & & \\
\hline & Jumlah 34 & 16 & 18 & & & & \\
\hline & Prosentase & 34: & $\mathbf{x 1 0}$ & - & 200 & (bail & \\
\hline
\end{tabular}

Tabel 4.6

Perolehan Skor Pemahaman dan Pembuatan RPP Siklus II

\begin{tabular}{|c|c|c|c|c|c|c|c|}
\hline \multicolumn{8}{|c|}{ Nama Guru : Subhanulfalah, ST } \\
\hline No & Indikator & 4 & 3 & 2 & 1 & $\%$ & Ket \\
\hline 1 & Identitas Mata Pelajaran & $\mathrm{v}$ & & & & 100 & Tinggi \\
\hline 2 & Kompetensi Inti & $\mathrm{v}$ & & & & 100 & \\
\hline 3 & Kompetensi Dasar & $\mathrm{v}$ & & & & 100 & \\
\hline 4 & Indikator Pencapaian Kompetensi & & $\mathrm{v}$ & & & 75 & Sedang \\
\hline 5 & Tujuan Pembelajaran & & $\mathrm{v}$ & & & 75 & \\
\hline 6 & Materi Pembelajaran & & $\mathrm{v}$ & & & 75 & \\
\hline 7 & Model dan Metode & & $\mathrm{v}$ & & & 75 & \\
\hline 8 & Kegiatan Pembelajaran & & $\mathrm{v}$ & & & 75 & \\
\hline 9 & Media, Alat/Bahan, dan Sumber Belajar & $\mathrm{v}$ & & & & 100 & \\
\hline 10 & Penilaian Pembelajaran, Remedial dan Pengayaan & $\mathrm{v}$ & & & & 100 & \\
\hline & Jumlah 35 & 20 & 15 & & & & \\
\hline & Prosentase & & $35: 40$ & & -0 & $0 \%(\mathrm{~B}$ & aik) \\
\hline
\end{tabular}

Tabel 4.7

Perolehan Skor Pemahaman dan Pembuatan RPP Siklus II

\begin{tabular}{|c|c|c|c|c|c|c|c|}
\hline \multicolumn{8}{|c|}{ Nama Guru : Tessa W, ST } \\
\hline No & Indikator & 4 & 3 & 2 & 1 & $\%$ & Ket \\
\hline 1 & Identitas Mata Pelajaran & $\mathrm{v}$ & & & & 100 & Tinggi \\
\hline 2 & Kompetensi Inti & $\mathrm{v}$ & & & & 100 & \\
\hline 3 & Kompetensi Dasar & $\mathrm{v}$ & & & & 100 & \\
\hline 4 & Indikator Pencapaian Kompetensi & & & $\mathrm{v}$ & & 75 & Sedang \\
\hline 5 & Tujuan Pembelajaran & & $\mathrm{V}$ & & & 75 & \\
\hline 6 & Materi Pembelajaran & $\mathrm{V}$ & & & & 75 & \\
\hline 7 & Model dan Metode & & $\mathrm{V}$ & & & 75 & \\
\hline
\end{tabular}


8 Kegiatan Pembelajaran

9 Media, Alat/Bahan, dan Sumber Belajar

10 Penilaian Pembelajaran, Remedial dan Pengayaan Jumlah 33

Prosentase

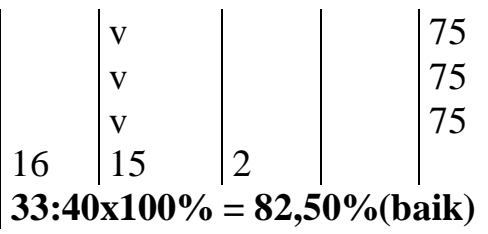

Tabel 4.8

Perolehan Skor Pemahaman dan Pembuatan RPP Siklus II

\begin{tabular}{|c|c|c|c|c|c|c|c|}
\hline \multicolumn{8}{|c|}{ Nama Guru : Eman Sulaeman, S.Pd } \\
\hline No & Indikator & 4 & 3 & 2 & 1 & $\%$ & Ket \\
\hline 1 & Identitas Mata Pelajaran & $\mathrm{v}$ & & & & 100 & Tinggi \\
\hline 2 & Kompetensi Inti & $\mathrm{v}$ & & & & 100 & \\
\hline 3 & Kompetensi Dasar & $\mathrm{v}$ & & & & 100 & \\
\hline 4 & Indikator Pencapaian Kompetensi & & & $\mathrm{v}$ & & 75 & Sedang \\
\hline 5 & Tujuan Pembelajaran & & $\mathrm{v}$ & & & 75 & \\
\hline 6 & Materi Pembelajaran & & $\mathrm{v}$ & & & 75 & \\
\hline 7 & Model dan Metode & $\mathrm{v}$ & & & & 75 & \\
\hline 8 & Kegiatan Pembelajaran & & $\mathrm{v}$ & & & 75 & \\
\hline 9 & Media, Alat/Bahan, dan Sumber Belajar & & $\mathrm{v}$ & & & 75 & \\
\hline 10 & Penilaian Pembelajaran, Remedial dan Pengayaan & $\mathrm{v}$ & & & & 100 & \\
\hline & Jumlah 34 & 20 & 12 & 2 & & & \\
\hline & Prosentase & 34: & $0 \times 1$ & $0 \%$ & & $00 \%($ & aik) \\
\hline
\end{tabular}

\section{Pembahasan}

Berdasarkan data di atas, pada pelaksanaan tindakan siklus I terlihat guru-guru masih belajar memahami dalam pembuatan RPP Kurikulum 2013. Hal ini dapat dilihat dari perolehan skor Yeri Maesuri, S.Pd mendapat skor $\mathbf{5 7 , 5 0 \%}$, Subhanulfalah, S.T mendapat skor $\mathbf{5 5 , 0 0 \%}$, Tessa W, ST mendapat skor $52,50 \%$ dan Eman Sulaeman, S.Pd mendapat skor $\mathbf{5 2 , 5 0 \%}$. Hasil evaluasi pada siklus pertama mencapai rata-rata $\mathbf{5 4 , 3 8 \%}$. Artinya guru-guru masih dalam tarap pembelajaran dalam memahami dan membuat RPP Kurikulum 2013.

Untuk memperbaiki kelemahan dan mempertahankan keberhasilan yang telah dicapai pada siklus pertama, maka untuk pelaksanaan siklus kedua dibuat perencanaan sebagai berikut.

1. Memberikan motivasi kepada guru-guru agar lebih aktif lagi dalam memahami dan membuat RPP Kurikulum 2013.

2. Lebih intensif lagi membimbing guru-guru dalam mememahami dan membuat RPP Kurikulum 2013

3. Memberi pengakuan atau penghargaan (reward).

Pada pelaksanaan siklus II terlihat para guru-guru sudah memahami dalam pembuatan
RPP Kurikulum 2013. Hal ini dapat dilihat dari perolehan skor Yeri Maesuri, S.Pd pada siklus I mendapat skor $\mathbf{5 7 , 5 0}$ dan pada siklus II skor $\mathbf{8 5 , 0 0 \%}$, Subhanulfalah, S.T pada siklus I mendapat skor $\mathbf{5 5 , 0 0 \%}$ dan pada siklus II skor $\mathbf{8 7 , 5 0 \%}$ dan Tessa W, ST pada siklus I mendapat skor $\mathbf{5 2 , 5 0 \%}$ dan pada siklus II skor $\mathbf{8 2 , 5 0 \% , ~ E m a n ~ S u l a e m a n ~ S , P d ~ p a d a ~ s i k l u s ~ I ~}$ skor $\mathbf{5 2 , 5 0 \%}$ dan pada siklus II skor $\mathbf{8 5 , 0 0 \%}$

Hasil evaluasi pada siklus II mencapai rata-rata $\mathbf{8 5 , 0 0 \%}$. Sedangkan siklus I rata-rata $\mathbf{5 4 , 3 8 \%}$. Artinya ada peningkatan $30,62 \%$. Hal ini menunjukkan bahwa guru-guru sudah memahami dalam pembuatan RPP Kurikulum 2013.

\section{PENUTUP}

\section{Simpulan}

Berdasarkan hasil penelitian tindakan sekolah dapat disimpulkan sebagai berikut:

1. Penerapan pembimbingan dan pelatihan dapat meningkatkan pemahaman dan keterampilan guru-guru mata pelajaran di sekolah binaan dalam pembuatan RPP Kurikulum 2013. Hal ini dapat dilihat dari kenaikan nilai rerata pada siklus pertama 


\section{Usep Saepudin}

Meningkatkan Kompetensi Guru Dalam Menyusun Rencana Pelaksanaan Pembelajaran Kurikulum 2013 Melalui Pembimbingan Dan Pelatihan Profesional Oleh Pengawas Sekolah Di SMK Galunggung

Kota Tasikmalaya Tahun 2016

$54,34 \%$ dan siklus kedua $85,00 \%$. Kenaikan $30,66 \%$

2. Guru-guru mata pelajaran di sekolah binaan sudah memahami dan mampu membuat RPP Kurikulum 2013 sesuai panduan RPP yang dikembangkan oleh Direktorat Pembinaan SMK tahun 2016 tentang pengembangan RPP Kuriklum 2013.

3. Guru-guru mata pelajaran di sekolah binaan sudah meningkat pemahaman dan keterampilannya dalam membuat RPP Kurikulum 2013. Hal ini dapat dilihat dari perolehan nilai rerata Yeri Maesuri, S.Pd pada siklus I mendapat nilai rerata $57,50 \%$ dan pada siklus II $85,00 \%$, Subhanulfalah, S.T pada siklus I mendapat nilai rerata $55,00 \%$ dan pada siklus II 87,50\%, Tssa. W,ST pada siklus I mendapat nilai rerata 52,50\% dan pada siklus II 82,50\%, dan Eman Sulaeman, S.Pd pada siklus I mendapat nilai rerata $52,50 \%$ dan pada siklus ke II $85,00 \%$.

\section{DAFTAR PUSTAKA}

Kemdiknas, 2011, Penelitian Tindakan Sekolah, Suplemen Materi Pelatihan Penguatan Kemampuan Kepala Sekolah, PPTKBPSDM dan PMP

Kemdikbud, 2015, Penelitian Tindakan Sekolah (PTS), Materi Pelatihan Penguatan Kemampuan Pengawas Sekolah, Karanganyar, LPPKS Indonesia

Kemdikbud, 2015, Supervisi Akademik, Materi Pelatihan Penguatan Kemampuan Pengawas Sekolah, Karanganyar, LPPKS Indonesia

Kusnandar, 2006, Langkah Mudah Penelitian Tindakan Kelas Sebagai Pengembangan Profesi Guru, Jakarta, Rajagrafindo.

Purwanto, Ngalim. 2004. Psikologi Pendidikan. Bandung : PT. Remaja Rosda Karya

Zainal Aqib dan Elham Rohmanto. 2007. Membangun Propesionalisme Guru dan Pengawas Sekolah, Bandung : Yrama Widya 
Jurnal Artefak:

History and Education, Vol.6 No.1 April 2019 